\title{
Science Fiction Cinema in Science Education and the Development of Future Thinking Visions....Aspirations
}

\section{Prof. Dr. Nahed Abdel-Radi}

A Professor of Curriculum and Instruction

Faculty of Education - Minia University

\section{Abstract;}

7 his paper deals with the concept of science fiction cinema, where science fiction is an

1 anticipation of what can happen in the future in light of scientific explanations of natural phenomena. Science fiction films have global mass popularity due to their special effects, and they are among the important methods for science education because of their development The learners' ability to have creative and critical thinking skills, and to increase their ability to learn scientific concepts in an interesting manner. It also helps them predict future scientific discoveries and inventions, and contributes to developing the dimensions of future thinking, which is one of the types of thinking related to future foresight. Despite the importance of science fiction films, there are shortcomings in using them to teach science. The current paper recommended the necessity of enriching science curriculum with science fiction literature, and including science fiction cinema as one of the methods of teaching science within the teaching methods curriculum of teacher preparation programs at the College of Education.

Keywords: Science fiction cinema - science education future thinking

\section{Introduction:}

Science fiction is a mirror that reflects the latest achievements in the field of science, and provides scientists with ideas that are invested and referred to as new innovations and discoveries. Science fiction is a vision of the possible future, and it contributes to the development of 
science and technology and is one of the important entrances to developing creativity and preparing future scientists.

Cinema films are considered among the best methods that presented science fiction literature, thanks to the progress achieved by advanced cinematic technology in special and visual effects and its ability to put impossible events and developments within the reach of the viewer, and the popularity of science fiction films has developed into a global mass popularity over the decades due to its close association with action films. And exciting adventures as a result of the use of technological effects, including depicting events that occur on planets and other galaxies, as well as missiles, battles, weapons, explosions, spacecraft and supernatural and strange creatures. All of these factors enhance the direction, photography and scenario that have been associated with science fiction films

One of the factors that make science fiction literature vital in the classroom is the increasing importance that the world currently attaches to futuristic studies. The results of some studies have confirmed the role of science fiction in achieving the goals of teaching science in the different educational stages, on top of which are creative thinking and talent. As the study of (Dahdol, 2020).

The future is specifically in itself, comes loaded with challenges and changes, and it has become imperative for nations to develop their thinking strategies in the future to 
interact with new scientific phenomena. It has become necessary that curricula and teaching methods, especially in our Arab world, contribute to positive interaction with future challenges at all stages of education. Through all curricula, especially science curricula, sensing those challenges and preparing to face them and moving from the level of thinking in reality to the level of future. .

\section{The difference between science fiction and literary} fiction:

The beginnings of scientific literature is the ancient literature, or the so-called utopia, which means "no place." It means a figment of the imagination of a society that differs entirely, negatively or positively, from the society in which the author of utopia lives, as stated in the novel Utopia of the author Tawfiq (2008), and this word means, as explained by Thomas More "The ideal place or utopia" (Abdelhamed, 2009). The word entered the language dictionary in (1915) through the title of his famous book, which describes an island with an ideal system somewhere in the New World, and through it Moore set a model for future utopia stories.

Science fiction literature is the imagination of a scientifically educated novelist who follows the achievements of science, follows up on the achievements of science, and his writings are launched through his imaginations freely unleashed among planets, in depths, with creatures and across time, taking from the achievements of science a starting point for him that opens 
his writings to the horizons of the universe to unite man with him and make him become an environment of infinite breadth. Familiar and inhabited, this writer who uses science fiction is a reader who sees the age of information technology, inventions and amazing scientific discoveries, and he is not the writer who looks into the world of ghosts, superstitions and Magic.

Looking at many scientific achievements that were achieved during the second half of the twentieth century and the beginning of the twenty-first century, starting with space travel and ending with gene therapy and cloning, we find that all these facts and scientific achievements were previously predicted in the science fiction literature since the late nineteenth century. That French writer "Jol Verne", who was the first to establish science fiction literature - had written his masterpiece "From Earth to the Moon" in 1865, "Imagine a trip to the moon, and this fantasy was actually achieved a century later, specifically in 1969 the first human being landed the surface of the moon, as imagined by the British science fiction writer Herbert Wells in his novel "The World Free" by discovering and liberating atomic energy in 1914, and the American physicist Leo Szilard benefited from this novel and was able to base on these predictions the project of making the atomic bomb 1945.

The foregoing, science fiction depends on the scientific fact in which the literary or novel work is transmitted. While literary fiction depends on the field of cultures and 
sciences, some interested people see the necessity of having a scientific expert when writing in science fiction for a certain field (Alnajjar, 2008)

Science fiction is a type of studied scientific literature based on scientific achievements and future technical developments. It is often associated with space, life on other planets, future cities, and the alternative world.

Science fiction has many definitions, and it does not have a comprehensive and complete definition because it contains many dimensions that distinguish it from other arts, including that it is a disciplined imagination based on practical assumptions, and therefore its events are achievable in the future, and it is closely related to man through his perception of the future and warning him of danger of the Coming. (Rashid, 2007) (Imran, 2006).

Webster's dictionary defines science fiction as that kind of fictional literature that deals with what is reflected in the current reality, or imagination based on science in accordance with the trends of society and its members. It is defined by (Robin, 2006) as the individual's ability to anticipate what will happen in the future in the light of scientific explanations of scientific phenomena.

In the current paper, science fiction is defined as a mental activity carried out by an individual that includes a predictive vision based on studied scientific hypotheses, in which he imagines what science can bring about in terms of future variables to solve private and societal problems. 


\section{Science fiction between fantasy and futurology:}

Science fiction is a kind of literary art where the author builds an imaginary world using physical, biological, technological or philosophical theories. The fantasy that imagines things that are impossible to achieve, and treats other worlds such as elves, dwarves or giants. Therefore, it does not provide an addition to reality.

Also, science fiction differs from fantasy and future sciences in that it is based on the achievements of a wellstudied reality, and on possibilities that almost reach certainty thanks to the easy achievements of scientific and technological progress. The famous writer "Isaac Asimov" explained the limitation of science fiction on a specific scale, which is the future, while there are many science fiction stories and novels that talk about the past and the present, which is what the British Encyclopedia took, where it defined science fiction as "that literature that deals with a scientific discovery or development, whether in the future or in the present, or in the past that is superior or different from the present." (Al-Dulaimi, 2018)

\section{Science fiction cinema:}

Movies are characterized by a global audience turnout by the majority of society segments, and they are no longer limited to being a means of entertainment, but rather contribute to the formation of personal identity, thought and general culture, and the term cinema is derived from cinematograph and means kinetic recording, and it has 
several types such as silent cinema, American cinema, commercial cinema and others .

There is no doubt that the flourishing of science fiction in literature in general, and cinema in particular, was a healthy indicator of the flourishing of science on the one hand, and its closeness to people, and then enjoyment of its stories on the other hand .

Since its inception in the early twentieth century in the era of silent cinema, science fiction films have been influenced by international literature and by comic strips that are widely spread in American newspapers and magazines, and which have achieved mass popularity throughout the ages. Millions of readers have followed these series daily for many decades. It would encourage these readers to watch science fiction films based on them when they are shown .

Science fiction films have gained such wide public popularity in the United States of America thanks to the progress achieved by cinematic technology in visual effects and their ability to put impossible events and developments in the viewer's view by displaying them on the screen, and their popularity has developed globally due to their close association with action films and exciting adventures of which they form a part.

American cinema in the era of silent cinema presented a number of distinguished films that combined science fiction and horror, the most famous of which were the 
movie "Sherlock Holmes" (1900), the movie "Twenty Thousand Leagues Under the Sea" (1905), the movie "Frankenstein" (1910), The Lost World" (1925). All of them are based on novels by international writers and authors .

Science fiction films witnessed a remarkable increase in Hollywood production in the 1930s and 1940s, and this also continued in the 1950s and 1960s in films such as "Journey to the Center of the Earth" (1959) and the movie "2000 A Journey to Space" (1968), and science fiction films achieved a boom Big in the seventies and eighties in films such as "Star Wars" (1977) and "I. T - Creature from Outer Space" (1982). Science fiction films continued to be produced and became popular in films such as "Journey to the Center of the Earth" (2008). ) and "Avater" (2009), "Guardians of the Galaxy" (2017), and science fiction presented in literature and cinema an independent vision based on an extension of our contemporary world .

Science fiction films presented space flights as a model for what man can achieve in his exploration of outer space. Many old films predicted events, equipment, devices, and advanced means of transportation that turned into realistic facts years or decades after man landed on the moon and the emergence of robots and robots .

The global popularity of science fiction films was reflected in the records of their total global revenues in cinemas around the world, as it occupies the first place in the total global revenues, followed by action and adventure 
films in second place. The movie "Avatar" (2009) ranked first in the list of films that achieved the highest revenues, amounting to 2,788 billion dollars. It deals with the latest advances in technology in the history of cinema. However, it presents a story of dimensions and a human anti-war and pro-nature message. This film constitutes a technological breakthrough, as it uses a new generation of special effects. The film includes unprecedented visual details, as almost all the scenes shown in the planet covered by the film's story, including the inhabitants of the planet, are made by special effects that display everything with convincing realism .

It is clear from the above that cinema in general constitutes the awareness and culture of peoples, and science fiction cinema in particular enjoys the interest of majority of global audiences. It embodies literary novels that deal with supernatural scientific phenomena and exciting natural phenomena using special techniques, visual and sound effects, which contribute to transferring the viewer's imagination to the future .

\section{Science fiction cinema in the Arab world :}

As for the history of cinema in the Arab world, science fiction was not completely absent from the literary arena. Rather, it was one of the subjects of Arab literature, and science fiction literature among Arabs remained governed by historical and cognitive conditions related to the extent of Arab scientific progress, which is less in size than what is the case in the West . 
Among the Arab writers who wrote in science fiction literature is "Tawfiq al-Hakim," where he wrote the play "Journey to Tomorrow" (1957), and "Mustafa Mahmoud" published in the sixties of the last century the two novels "The Spider" and "Man Below Zero." I wrote "Nuhad Sharif" The novel "Qaher al-Zaman" was written by the Kuwaiti writer "Tiba al-Ibrahim," a pioneer of science fiction literature in the Arab Gulf, "The Pale Man." It was the first production of an Arab movie in 1927, an Egyptian film, followed by the production of a Syrian, then Iraqi and Algerian film. However, the Egyptian cinema is considered the most diverse and rich in Arab film production .

With regard to the reality of the demand for watching science fiction films in the Arab world, the search statistics on the YouTube platform and the famous search engine Google indicate an increase in the percentage of clips in Arabic that deal with fictional and exciting films, and this indicates the extent of the interest of a large segment of viewers to this type of cinematic films that gives them the opportunity to sail their imagination in the world of the universe, space and the depths of the sea .

Based on the foregoing, cinema is an important tool and method in the educational system in general and science education in particular. It has a key role in forming the thought and culture of learners and takes them great strides towards progress and advancement. Educational films, despite the diversity of modern teaching methods, are characterized by embodying reality and reflecting Images 
and phenomena that are difficult to notice, in addition to adding a side of fun, suspense and excitement to learners, which achieves learning goals and makes it lasting. .

In order to develop science fiction among learners, the use of science fiction films in science education has become an urgent necessity, as indicated by the Egyptian scientist, "Ahmed Zewail," who won the Nobel Prize in Chemistry in 1999." What made America ahead of the world scientifically is its use of science fiction in science education" (Ismaael, 2010) because of its importance, which is evident in the following :

- Teaching scientific concepts in an interesting, exciting and fun way.

- Developing creativity, problem-solving skills and critical thinking ability.

- Developing higher-order thinking skills and imaginative meditation skills

- Forming a positive attitude among learners towards accepting change and preparing them to accept what the world will be like in the future.

- Stimulating learners' thinking to find various solutions to the same problem .

- Activating the minds of learners through the ability to predict future.

Developed countries realized the role of science fiction in preparing and nurturing a generation of scientists and innovators, so they included it in various educational curricula, and opened study departments in a number of 
universities specializing in science fiction literature, and confirmed that the study of science fiction is an integral part of future strategies .

The literature agreed that science fiction includes several dimensions and elements of its statement, as follows :

- Time frame such as being in the future.

- Spatial framework such as outer space or in other worlds.

- Characters like aliens from space, androids, robots

- Futuristic technology such as laser cannons, computers

- New scientific principles such as time travel, wormholes, travel faster than light.

- Supernatural abilities: such as controlling the mind and being in two places at the same time.

- Universes and other dimensions and travel between them.

It is clear from the previous elements of science fiction that it is closely related to the branches of natural sciences, which contributes to its development among learners while they learn science and gives them the ability to visualize and imagine, as it is a necessary entrance to the development of creativity and future thinking, and early detection of creators and distinguished to ensure the preparation of a generation of scientists and creators in various fields of science and knowledge to occupy our Arab world a prominent place in the world of the future . 
Therefore, science fiction cinema is one of the most important methods of science education that can embody the dimensions and elements of science fiction represented in the time frame and often in the near or distant future, and the spatial frame may be on Earth or planets or in any part of the universe or on Imaginary places like parallel universes based the facts, principles, hypotheses, physical and biological theories of science and others .

Science fiction films reflect its characteristics, as they take from scientific phenomena future expectations and predictions, and their reflection on the future world and human destiny, in an interesting and exciting dramatic form, and employ these films in teaching natural sciences to contribute to the development of future thinking of learners .

\section{What is future thinking:}

The world in which we live now is rapidly changing, especially in the field of inventions and technology, and is surrounded by challenges in global scientific issues represented in genetic engineering, space reconstruction, artificial intelligence and others. All of this requires speed in developing minds capable of innovation, and prediction of the variables that the future brings .

Jones, et.al, (2012)) define future thinking as an organized exploration of the future that encourages analysis, criticism, evaluation and visualization of solutions for a better future. It is also defined by (Hines \& Bishop, 2006, 13) as a connected thinking that passes through the 
following stages: imagination, expansion, prediction, visualization, planning, and decision-making.

Viderger, et.al, $(2019,19)$ define it as the ability to discover, study, and propose future scenarios for some situations and issues, as learners have an important role to play in scrutinizing future fantasies and perhaps even influencing the way they dream in the future to be aware of future developments .

Future thinking is defined in the current paper as that kind of thinking that relates to anticipating the future in the light of understanding the present and it includes a set of skills that the learner must acquire to enable him to foresee, namely planning, prediction, imagination, and visualization

The literature agreed that future thinking skills are as follows :

\section{Intuitive forecasting skill :}

It is a process of new processing of information that enters the cognitive structure of the individual, followed by a sudden manifestation of it in a way that has modernity and creativity. The sub-skills are emotional understanding, holistic awareness of relationships .

\section{Scientific prediction skill:}

A mental process based on the individual's use of his previous scientific experiences and his current reality to build perceptions that the phenomena will be in the future. The sub-skills are exploratory prediction and normative prediction . 


\section{Visualizing future skill :}

A mental representation through which a picture of future scientific procedures is formed, through which the individual can build realistic ideas that benefit society. The sub-skills are planning and contemplative criticism .

The study of (Cathy, et.al, 2013) also identified the skills of future thinking in induction, prediction, analysis, and development of future scenarios .

Based on the foregoing, the skills of future thinking are summarized in prediction, visualization, analysis, and extrapolation of the future, which are features of future science, and it is necessary to develop them among learners while learning science to help them face the challenges of the twenty-first century with all its variables and developments, which impose themselves on science curricula such as scientific issues Dialectics such as energy, water, food, the human genome, biotechnology, etc., require a creative thinker, stable, imaginative, capable of making decisions .

The literature has identified the importance of developing future thinking skills among learners in the following :

- Helping to develop learners' ability to build the world they want to live in

- Helping learners to be creative, imaginative, and envision better solutions for a distinguished future . 
- enhancing learners' creative abilities by reviewing their past experiences and future expectations and enabling them to predict future changes .

- Helping to increase self-confidence to face the future and its problems

- Helping in the search for future solutions to solve contemporary problems.

Based on the importance of developing the future thinking skills of learners, it should be one of the most important objectives of teaching science at all educational levels in order to anticipate future prospects, using teaching methods based on science fiction, and cinematographic films in particular play a key role in developing the learners' ability to predict future science related to the topics that are being taught. Teaching science fiction through it .

The report prepared by UNESCO experts to the International Committee on Education for the Twenty-first Century, entitled "We Learn to Be", confirms that in a highly changing world, one of its main engines appears to be both social and economic renewal, and space must be given to imagination and creativity, as they represent the clearest manifestations of freedom of Man, as the twentyfirst century requires this diversity and creativity.

However, despite the importance of science fiction in developing future thinking, which was confirmed by the results of a study (Nada 2012), which showed the effectiveness of an approach based on science fiction in 
teaching science to develop future thinking skills and scientific survey for preparatory stage students, there are shortcomings in the use of science fiction cinema in Science education, rather it is almost non-existent in our Arab world, where the focus is more on documentaries, which are specially prepared for showing in the classroom, and they are often devoid of the elements of suspense and excitement, and most educated people turn away from watching them .

This is consistent with what was mentioned (Abu Qura, 2014) that despite the increasing importance that the West attaches to science fiction literature and cinema, our Arab world has not witnessed similar or even commensurate interest with that importance. The reality of science fiction literature in our Arab world indicates that it is marginalized. It is rare and still modest in terms of production and the scarcity of specialized writers. This is due to the fact that this type of literature needs to communicate with modern scientific and technological developments, which is what the Arab writer lacks .

Also, one of the reasons that reinforce a poor cinematic reality in the Arab world is the absence of cinema as an effective creative and social practice, and the films that exist are nothing more than individual adventures, as well as the absence of theoretical and critical support, and the underestimation of the importance of follow-up and creativity activities, and most of what he writes are repercussions and impressions that lack depth of 
methodological coherence, and the educational system in the Arab world does not recognize what is related to cinema in the slightest, and it is impossible to find an educational institution in which cinema is used as a teaching material that can be addressed at all educational levels .

As a result of the absence of science fiction literature and cinema as methods in science education, the results of many studies, such as (Staley \& Malenfant, 2010),( Maciejewwski, 2016) (Mohamed, 2017) and (Mahmoud, 2018) confirm the low level of future thinking skills among learners at different educational stages .

Due to the scarcity of studies that dealt with science fiction cinema in science education or the formulation of the content of science curricula in the light of science fiction literature, the study (Al-Rahili, Al-Jabr, 2019) indicated the absence of the dimensions of science fiction in physics curricula at the secondary stage, as confirmed by the recommendations of the "19th Scientific Conference convened In Cairo in August 2019, "the need to pay attention to science fiction stories in the design of school curricula, and the study of (Afredo, 2016) which indicated the need to expand studies and research related to cinema and science teaching because of its importance and its reflection on the educational reality .

In light of what was previously presented and in response to the results of studies, the current paper recommends the following : 
- Interest in using science fiction cinema in science education at all educational levels .

- Providing cinematic screening mechanisms for science fiction films in the classroom.

- Inclusion in the natural sciences curricula for science fiction stories .

- Holding training courses for science teachers in the service on how to employ science fiction films in the classroom .

- Incorporating the science fiction cinema strategy into the preparation programs in the faculties of education with the Teaching Methods course for scientific people .

- The necessity of conducting several studies on the role of science fiction cinema in developing different ways of thinking .

\section{References :}

- Al-Zawawi, Mahmoud (2017). Science Fiction Cinema Link to World Literature and Comic Story Series, Afkar Magazine, Amman, Ministry of Culture (343) 26-31.

- Abd Alhameed, S (2009). Fantasy, inspiration and creativity in the primary stage, Second Scientific Conference (Arab Child Creativity), Faculty of Qualitative Education, Por Said, (12) 18-3 .

- Abdel Halim, Abbas (2017). Science Fiction Literature among the Arabs, Critical Reflections, Afkar Magazine, Amman, Ministry of Culture, (343) 32-37.

- Abu Al-Rub, Majdoleen (2017). "Science Fiction Literature", Afkar Magazine, Oman Ministry of Culture, (343) 19-20 .

- Abu Qura, Khalil (2014). Let's start with science fiction to develop creativity and talent, Middle East Arab International Newspaper https://aawsat.com/home/article/130006 (13002). 
- Abu Qura, Khalil and Salama, Safat (2006): Science Fiction and Enriching Creativity, Working Paper, Culture and Science Symposium, Dubai . Al-Dulaimi, Latifa (2017). Science fiction literature between fantasy and futurology, Afkar magazine, Amman, Ministry of Culture, (343) 21-25.

- Abul Khairat, Majidah (2016). A science fiction movie that tackles the highest grossing American cinema revenues. Available at https://wwwahdath.info/203044

Al Najjar, M (2008). Do you know about the difference between the science fiction and the free fantasy? It is in the following

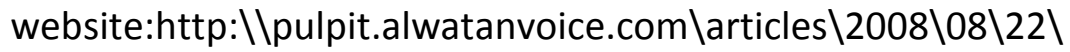
142890. html.

- Alfredo Menéndez-Navarro. (2016). The Challenge of introducing the cinema in the teaching of the bio health sciences. Revisit de Medicine y Cine / Journal of Medicine and Movies,( 7) 1-2.

- Al-Ruhaili, Amina and Al-Jabr, Jabr (2019). "Inclusion of dimensions of science fiction in the content of a physics book (2) for the secondary stage in the Kingdom of Saudi Arabia", International Journal of Research in Educational Sciences, International Foundation for Future Horizons, Tallinn, Estonia, pp. 355-384.

- Asala, Issam (2011). Science Fiction: Concept, Types, Functions, Arabic Language Academy (2) 107-137.

- Cathy P \& Hipkins, R,Mckim,A., Connr,L \& Saunders,K.(2013)." Developing Students Future Thinking in Science Education " Faculty of Education University Canterbury :// www. Alukah .net/social/0/95085/ \# ixzz5C RY 8u9Sp

- Dahdol, Nasreen Karim (2010). The effect of teaching using science fiction films on developing the creative thinking of tenth grade students in the light of their motivation towards learning the subject of life sciences in Jordan." The Jordanian Educational 
Journal, the Jordanian Association for Educational Sciences (2) 210-236 .

- Ghaly, Abdel Qader (1942). Cinema and Science Teaching, Science Teaching Conference, Cairo, Modern Education Association.

- Hafez, Emad Hussein (2015) future thinking (concept - skills strategies), Cairo, Dar Al Uloom for Publishing and Distribution.

- Harb, Magda and Al-Hamid, Khadija (2019). "The Teacher and Education Issues in the Egyptian Cinema", Journal of Human and Social Sciences Studies, (2) 417-427.

- Hines, A \& Bishop, P. (2006): Thinking About The Future, Guidelines for Strategic Foresight", Social Technologies LTC, Washington, pp 11-18, ISBN,( 13), 978-0-9789317.

- Imran, Talib (2006). Science Fiction, Modern Technology and Child Culture, Al-Mawqif Al-Adabiya Magazine, (42) 1-19.

- Ismael, M (2010). The logical reasoning of teachers of science in the performance of teaching and its relation to the development of science fiction among primary school students, Journal of Studies in Curricula and Teaching Methods. (155), 183-229.

- Jones ,A.,Bunttinng, C., Hipkins, Mckim, A., Conner,L.\& Saunders, K.(2012)." Developing Students Futures Thinking in Science Education ", Journal of Science Education (4), 687-708.

- Lehtonen, A. (2012): "Future Thinking and learning in Improvisation and A Collaborative Devised Theatre Project Within Primary School Students", *The 5th Intercultural Arts Education Conference: Design Learning.

- Liberko, C. (2004): Using science fiction to teach Thermodynamics, Journal of Chemical Education, 81, (4), 509.

- Maciejewski, W,\&Barton, B.(2016). "Mathematical Foresight: Thinking in the Future to Work in the Present ", Journal of Mathematics Education ,(30)20-30

- Maciejewski, w.(2019)." Future-Oriented Thinking and Activity in Mathematical Problem Solving", Department of Mathematics and 
, San Jos State University, one Washington Square, S Can Jose, CA,USA .

- Mahmoud, Iman Mahmoud Jaber (2018). The effectiveness of the STEM entrance in teaching science to develop future thinking skills and the trend towards integration among preparatory stage students, a master's thesis, Faculty of Education, Zagazig University.

- Mazen ,H(2008).Technology of the higher imagination of the Arab child in the age of internet, technology on satellite channels, conference on technology of education and teaching of the Arab child , Egypt , p p(110-145).

- Mohamed, Hanan Fawzy (2018). Evaluating science curricula for the third preparatory grade in the light of future thinking skills, Journal of Educational Sciences, Faculty of Education, Yaqna, South Valley University, (37) 264-304.

- Mohamed, Hanan Mahmoud (2017). A program based on the concepts of water security to develop some dimensions of sustainable development and future thinking skills of the student teacher, Arab Studies in Education and Psychology, (91), 399-429.

- Mohamed, Rania Mohamed Ibrahim (2019). The effectiveness of using the "REACT" strategy in developing future thinking skills and academic achievement motivation for second year preparatory students, Journal of the Faculty of Education, Benha University (19) 81-12.

- Nada, Shaima Hamed Abbas (2012). The effectiveness of a fantasy based approach in teaching science to develop future thinking skills and scientific inquiry for preparatory stage students, Ph.D. thesis, Faculty of Education, Helwan University.

- Nofal, M (2009). Creative creativity: Concepts and applications, Amman: Dibnf or Printing, Publishing and Distribution, Ministry of Education http://www.moe.gov.jo/Departmen.

- Qassem, Mahmoud (2018). Science Fiction Alamzadeh Al-Khayal, Cairo, Egyptian Book House. 
- Rashid, Ali (2007). Enriching and making science fiction among children, Cairo, Arab Thought House .

- Rashid, Ali (2010). Developing creativity and scientific imagination among kindergarten children, primary and preparatory stages, Amman, Debono House for Publishing and Distribution.

- Robin , D. (2006) . Science And The Imagination in The Age of Reason, Journal of Medical Humanities, United Kingdom, Scotland,(27), PP.58-63.

- Saleh, Taghreed (2018). Science Fiction Cinema, available at: https://www.makalcloud.com/post/3f1v6r31y.

- Staley,D. \& Malenfant, K(2010) . Futures Thinking for Academic Librarians : Higher Education in 2025, ACRL is a Division of the American Library Association Jun, htt://www.ala.org/acrl/files/ issues/value/ futures2025 .pdf .

- Suleiman, Tahani Mohamed (2017). "The effectiveness of a program based on scientific developments in developing future thinking and appreciating science and the efforts of scientists among the scientific students of the Faculty of Education", the Egyptian Journal of Scientific Education, the Egyptian Association for Scientific Education, (6) 1-36.

- Tawfiq, Ahmed Khaled (2008) Utopia, Cairo, Dar Al-Shorouk.

- Tsai,M.\& Lin,H.(2016) ."The Effect of Future Thinking Curriculum on Future Thinking and Creativity of Junior High School Students", Journal of Modern Education Review ,(3),176-182.

- Vidergor,H.Givon,M.\& Mendel,E.(2019)."Promoting Future Thinking in Elementary and middle School Applying the Multidimensional Curriculum Model" , Thinking Skills and Creativity , (31), 19-30.

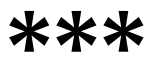

